\title{
Variants Near CETP, MTTP and BUD13-ZPR1-APOA5 may be Nominally Associated with Poor Statin Response among Filipinos
}

\author{
Lourdes Ella G. Santos, MD, ${ }^{1}$ Jose B. Nevado, Jr., MD, PhD, ${ }^{2}$ Eva Maria C. Cutiongco-de la Paz, MD, 1,3 \\ Lauro L. Abrahan IV, MD, ${ }^{1}$ Aimee Yvonne Criselle L. Aman, RCh, MD, ${ }^{2,3}$ Elmer Jasper B. Llanes, MD, ${ }^{1}$ \\ Jose Donato A. Magno, MD, ${ }^{1}$ Deborah Ignacia D. Ona, MD, ${ }^{1}$ Felix Eduardo R. Punzalan, MD, MSc, ${ }^{1}$ \\ Paul Ferdinand M. Reganit, MD, MPH, ${ }^{1}$ Richard Henry P. Tiongco II, MD, ${ }^{1}$ Jaime Alfonso M. Aherrera, MD, ${ }^{1}$ \\ Charlene F. Agustin, MD, ${ }^{1}$ Adrian John P. Bejarin, MD ${ }^{2,3}$ and Rody G. Sy, MD ${ }^{1}$

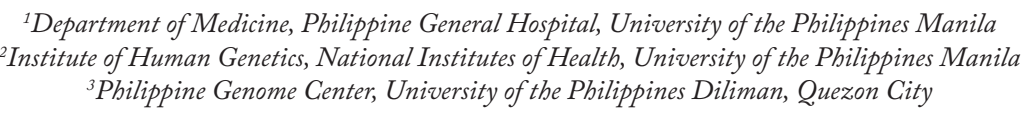

ABSTRACT

Objective. Several studies showed that genetic factors affect responsiveness to statins among different populations. This study investigated the associations of candidate genetic variants with poor response to statins among Filipinos.

Methods. In this unmatched case-control study, dyslipidemic participants were grouped into statin responders and poor responders based on the degree of reduction in LDL-c from baseline. DNA from blood samples were genotyped and analyzed. The association of candidate variants with statin response was determined using chi-square and logistic regression analysis.

Results. We included 162 adults on statins (30 poor responders as cases, 132 good responders as controls). The following variants are nominally associated with poor response to statin among Filipinos at a per-comparison error rate of 0.05: rs173539 near CETP (OR=3.05, $p=0.015)$, rs1800591 in MTTP (OR=3.07, $p=0.021)$, and rs1558861 near the BUD13-ZPR1-APOA5 region $(\mathrm{OR}=5.08, \mathrm{p}=0.004)$.

Conclusion. Genetic variants near CETP, MTTP and the BUD13-ZPR1-APOA5 region are associated with poor response to statins among Filipinos. Further study is recommended to test the external validity of the study in the general Filipino population.

Keywords: Filipino, BUD13-ZPR1-APOA5, CETP, lipid, MTTP, statin

Paper presented in the $25^{\text {th }}$ PLAS-PSH Joint Annual Convention- Crossing Bridges in Non-Communicable Diseases, "Updates on Cardiovascular Research in the Philippines" on February 27, 2020, at EDSA Shangri-la Hotel, Mandaluyong, Philippines.

Paper presented in the APSC 2019 Congress and PHA 50 th Annual Convention and Scientific Meeting, "Philippine Pharmacogenetic Data on Cardiovascular Medicine" on May 22, 2019 at SMX Convention Center, Pasay City, Philippines.

Paper presented in the 49 $9^{\text {th }}$ Annual Convention and Scientific Meeting, Philippine Heart Association, "Pharmacogenetics and Cardiovascular Care: the Future and Now" on May 25, 2018, at EDSA Shangri-la Hotel, Mandaluyong, Philippines.

Paper presented in the 67 th Joint AHA and ACC Annual Scientific Session and Expo, American College of Cardiology, "Ethnic differences in response to medication for ASCVD risk reduction: Insights from Pharmacogenomics" on March 11, 2018, at Orlando, Florida.

Corresponding author: Rody G. SY, MD

Section of Cardiology

Department of Medicine

Philippine General Hospital, University of the Philippines Manila

Taft Avenue, Ermita, Manila 1000, Philippines

Email: rodysymd@gmail.com / rgsy@up.edu.ph 


\section{INTRODUCTION}

Dyslipidemia is a disorder characterized by abnormalities in the lipids circulating in the blood. Around $47.5 \%$ of adult Filipinos aged 20 and older have elevated low density lipoprotein cholesterol (LDL-c) levels, with a mean LDL-c level of $131.5 \mathrm{mg} / \mathrm{dL}$ ( $8^{\text {th }}$ National Nutrition Survey - Clinical and Health Survey). Increasing prevalence of elevated levels of LDL-c and triglyceride, and decreased levels of highdensity lipoprotein cholesterol (HDL-c) among Filipinos ${ }^{1}$ pose a public health concern given their association with the development of atherosclerosis and other cardiovascular conditions. The World Health Organization's Global Health Observatory listed 233,190 total deaths due to cardiovascular diseases in the Philippines in 2016. The latest worldwide estimates show that more than half of the 2 million increase in deaths from 2000-2019 came from the WHO Western Pacific region, to which the Philippines belong. The control of risk factors such as elevated cholesterol levels may delay the development of atherosclerosis and cardiac death. ${ }^{2}$

Statins have been part of the standard of care since early 1990s as first-line agent for the prevention of coronary artery disease and other cardiovascular events., ${ }^{3,4}$ These drugs act primarily by inhibiting the rate-limiting enzyme HMG-CoA reductase in the synthesis of hepatic cholesterol, thereby upregulating hepatic LDL receptors and reducing the circulating LDL-c pool.

Although proven effective, there is considerable variability in response observed in patients under statin therapy that are not explained by clinical factors. A review demonstrated that Asian patients have better responses to statins compared to Western populations. ${ }^{5}$ Clinical trial evidence show that Asians achieve similar benefits as Westerners at lower statin doses. ${ }^{6-12}$ The potential mechanisms of increased response to statins among Asians are thought to be related to genetically-based differences at the level of hepatic enzymes and drug transporters.

Differences in statin response may be due to genetic polymorphism in cholesteryl ester transfer protein $($ CETP $),{ }^{13}$ solute carrier organic anion transporter family $1 B 1$ (SLCO1B1) ${ }^{14}$ and proprotein convertase subtilisin-kexin type 9 (PCSK9). ${ }^{15}$ CETP TaqIB polymorphism was studied in over 13,000 patients ${ }^{16}$ and has shown to be associated with modified HDL response, where individuals with the B1B1 genotype displayed the greatest HDL-c increases in response to statins in multiple studies. ${ }^{17,18}$ Among Filipinos, the CETP TaqIB polymorphism has also been implicated in HDL-c levels. ${ }^{19}$ The hepatic uptake of atorvastatin and simvastatin is facilitated by the organic anion-transporting polypeptide 1B1 (OATP1B1), encoded by SLCO1B1. Polymorphisms in $S L C O 1 B 1$ become potential targets for analyzing impact on statin lipid-lowering response, as these variants could affect OATP1B1 activity. Loss-of-function variants in genes encoding for PCSK9 have been shown to improve LDL-c reduction with statin use compared to non-carriers of these variants. ${ }^{20}$ In addition, a study showed that statins induce PCSK9 expression, thereby causing dampening of statin-induced LDL-c reduction through LDL receptor degradation. ${ }^{21}$ As a result, various inhibitors to reduce PCSK 9 levels are being studied. ${ }^{15}$

Despite the potential significance of genetic influences on statin response, there are no studies that specifically address this concern among Filipinos who remain underrepresented in published literature. This study, therefore, aims to fill this knowledge gap by determining the association of selected genetic variants with poor response to statins in the background of different clinical factors among Filipinos.

\section{MATERIALS AND METHODS}

\section{Study design and enrollment of participants}

This is an unmatched case-control study investigating the association of candidate variants and clinical factors with poor response to statins among Filipino adults. Participants from a public tertiary university hospital in Manila, different communities in Metro Manila, and private clinics volunteered to be included from July 2013 to March 2017.

We included Filipinos aged 18 years or older with dyslipidemia on statin therapy for a period of at least 16 weeks, if statin-naive, or at least 6 weeks if previously on moderate intensity statin therapy. Individuals with observed decrease in LDL-c levels of either $<50 \%$ on high-intensity statin doses or $<30 \%$ if on moderate-intensity statin doses (Supplementary Table 1) were classified as statin poor responders while those with observed decrease in baseline LDL-c levels of either $\geq 50 \%$ if on high-intensity statin doses or $\geq 30 \%$ if on moderate-intensity statin doses were classified as statin responders.

Participants were excluded if they had decompensated heart failure, decompensated chronic lung disease, decompensated chronic liver disease, end-stage renal disease, active malignancy, secondary hypertension, secondary dyslipidemia, or pregnancy. They were also excluded if they were related to other enrolled participants up to $3^{\text {rd }}$ degree of consanguinity. ${ }^{22,23}$

\section{Clinical data collection}

We obtained demographic and clinical characteristics of the participants, such as age, sex, co-morbidities, and smoking and alcohol use status from their patient records and from verbal interviews. Previous lipid profile levels prior to use of statins were also recorded from their clinical record. Lipid profile and serum creatinine results were obtained and recorded.

\section{DNA extraction and quantification}

DNA was extracted using the QiaAmp DNA Minikit (QIAGEN, Victoria, Australia), following the spin protocol for blood buffy coat specified in the manufacturer's instruction manual. DNA was quantified using a spectrometer at 


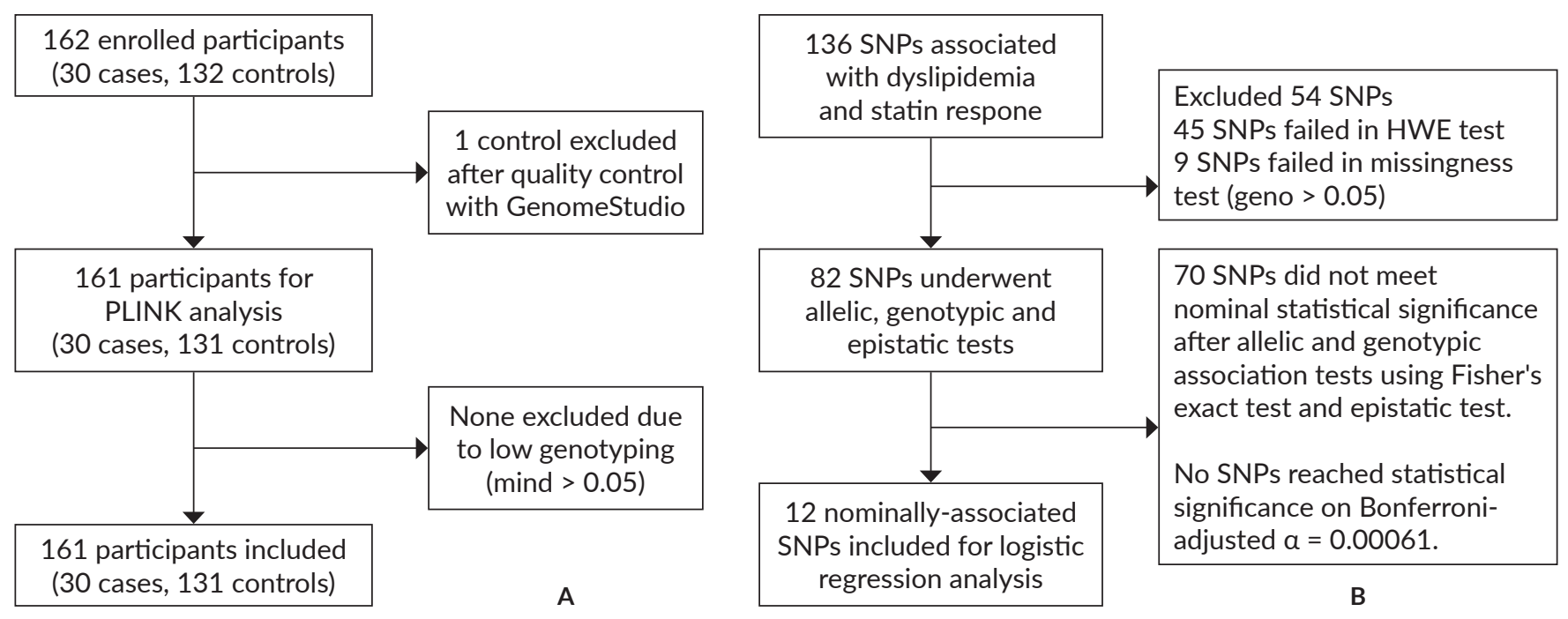

Figure 1. Overview of data processing and analysis. A total of 161 participants (A) and 82 SNPs (B) were analyzed to determine association of clinical metadata and genetic variants with poor response to statins.

SNP, single nucleotide polymorphism; HWE, Hardy-Weinberg equilibrium; geno, genotypic missingness; MAF, minor allele frequency

$260 \mathrm{~nm}$ and stored at $-20^{\circ} \mathrm{C}$ until use. All DNA samples had A-260nm/A-280nm value above 1.80 . These were similar to the methods in earlier published studies by the authors. ${ }^{22,23}$

\section{Genotyping}

Researchers from the Microarray Core Laboratory of the Institute of Human Genetics of the National Institutes of Health-University of the Philippines designed a customized GoldenGate Genotyping (GGGT) BeadChip (Illumina, Inc., San Diego, CA, USA) in 2012 using candidate single nucleotide polymorphism (SNPs) from both coding and noncoding regions, including 136 SNPs which have shown evidence of association with statin response and lipid metabolism (Table 6). These were selected after a

Table 1. Clinical characteristics of study participants

\begin{tabular}{|c|c|c|c|}
\hline Variable & $\begin{array}{l}\text { Poor responders } \\
\text { to statin }(n=30)\end{array}$ & $\begin{array}{l}\text { Responders to } \\
\text { statin }(n=131)\end{array}$ & $p$ value \\
\hline Age $\geq 60$ years old, $\%$ & 50.00 & 52.67 & $0.79^{*}$ \\
\hline Sex, \% males & 56.67 & 51.91 & $0.64^{*}$ \\
\hline \multicolumn{4}{|l|}{ Co-morbidities, \% } \\
\hline Elevated $\mathrm{BMI} \geq 25 \mathrm{~kg} / \mathrm{m}^{2}$ & 50.00 & 47.69 & $0.83^{*}$ \\
\hline Hypertension & 86.67 & 75.57 & $0.19^{*}$ \\
\hline Type 2 diabetes mellitus & 46.67 & 42.75 & $0.70^{*}$ \\
\hline Ischemic Stroke & 20.00 & 10.69 & $0.16^{*}$ \\
\hline Ischemic Heart Disease & 56.67 & 42.75 & $0.17^{*}$ \\
\hline Smoker, \% & 40.00 & 41.54 & $0.88^{*}$ \\
\hline Alcohol use, $\%$ & 60.00 & 60.77 & $0.94^{*}$ \\
\hline \multicolumn{4}{|l|}{ Laboratory results, mean (SD) } \\
\hline eGFR, ml/min & $74.62(26.14)$ & $84.77(26.51)$ & $0.06^{\dagger}$ \\
\hline Total cholesterol & $202.38(52.48)$ & $177.35(48.75)$ & $0.01^{\dagger}$ \\
\hline Triglycerides, mg/dl & $147.79(70.26)$ & $125.44(66.19)$ & $0.10^{+}$ \\
\hline HDL-c, mg/dl & $48.88(13.97)$ & $51.52(15.79)$ & $0.40^{\dagger}$ \\
\hline LDL-c, mg/dl & $128.03(39.92)$ & $101.39(39.96)$ & $0.0012^{\dagger}$ \\
\hline Mean percent change in LDL-c level & 19.06 & 53.05 & $<0.0001^{\dagger}$ \\
\hline
\end{tabular}

$B M I$, body mass index; eGFR, estimated glomerular filtration rate; HDL, high-density lipoprotein;

LDL, low-density lipoprotein

*Significance set at $p<0.05$ using chi-squared test

tSignificance set at $p<0.05$ using $t$-test 
comprehensive search was done in the following databases: Pharmacogenomics Knowledgebase (PharmGKB) database, National Human Genome Research Institute GenomeWide Association Study (NHGRI GWAS) Catalog, PubMED and patent databases (e.g., Patentscope and Espacenet) where odds ratios (ORs) for risk and protective effects were provided. While the microarray platform used is optimally designed to detect bi-allelic SNPs, the study included tri- or quad-allelic SNPs in cases where the variants have been correlated with significant clinical outcomes. The selected SNPs were submitted to Illumina, Inc. for scoring to determine the suitability of the SNPs to discriminate genetic variants, as well as estimate their specificity.

Customized genotyping of candidate SNPs was performed using DNA microarray technology following the GGGT assay protocol specified in the manufacturer's manual. After microarray processing, the BeadChip was imaged on the HiScan System and data from these images were analyzed using GenomeStudio software. The variant selection and genotyping methods were similar to methods in previously published studies. ${ }^{22,23}$

\section{Data analyses}

\section{Quality control}

To ensure high quality data, GenomeStudio 2.0 and PLINK version 2.05 .10 were used to identify and remove participants and markers that may lead to false-positive and false-negative associations. Genotype data from participants with call rates $>95 \%$ after evaluation with GenomeStudio and with individual missingness $<0.05$ (missingness test) in PLINK were included. The following thresholds were used for the genotype data: minor allele frequency of 0.01 (frequency test), genotype missingness of 0.05 (missingness test), and Hardy-Weinberg Equilibrium (HWE) of controls of $\mathrm{p}<0.001$ (HWE test).

\section{Statistical analysis}

Initial determination of genotypic effect was done. We determined significant differences between alleles and genotypes, i.e., allelic and genotypic association tests (additive, dominant and recessive effects) using Chi-squared and Fisher exact tests were performed to assess for. These were identified based on the distribution of the case and control genotypes. Tests for allelic and genotypic associations were done setting the cut-off at the per-comparison error rate (PCER) of 0.05 to avoid exclusion of SNPs that may be restricted by Bonferroni correction.

Upon determination of genotypic effects, the genotypes were recoded according to the significant effect for logistic regression analysis. Univariate logistic regression analysis was done to determine association of SNPs with poor response to medication, with cut-off $\mathrm{p}$-value set at 0.05 . Multiple logistic regression was performed to account for the effects of clinical factors in the odds ratio of the variants (Table 2).

Quality control and statistical analyses were similar to the methods in studies published earlier by the authors. ${ }^{22,23}$

\section{Ethical considerations}

The University of the Philippines Manila-Research Ethics Board reviewed all procedures for compliance with its ethical standards. All participants who volunteered to join the study signed a written informed consent form prior to their interview, chart review and blood extraction. All methods were carried out in accordance with relevant guidelines and regulations.

Table 2. Crude and adjusted ORs of significant clinical and genetic factor

\begin{tabular}{|c|c|c|c|c|c|}
\hline \multicolumn{2}{|c|}{ Factors } & \multicolumn{2}{|c|}{ Crude OR $(95 \% \mathrm{Cl})^{*}$} & \multicolumn{2}{|c|}{ Adjusted OR (95\% Cl) } \\
\hline Hypertension & & 2.10 & $(0.68,6.48)$ & 4.25 & $(1.08,16.77)$ \\
\hline \multirow[t]{2}{*}{ rs776746 } & (TC vs TT) & 1.70 & $(0.55,5.28)$ & 0.88 & $(0.24,3.26)$ \\
\hline & (CC vs TT) & 3.10 & $(1.01,9.45)$ & 1.77 & $(0.44,7.17)$ \\
\hline rs2032582 & (TT vs TG/GG) & 4.09 & $(1.38,12.09)$ & 1.60 & $(0.42,6.02)$ \\
\hline rs1558861 & (TC/CC vs TT) & 2.89 & $(1.03,8.05)$ & 6.98 & $(0.97,50.21)$ \\
\hline \multirow[t]{2}{*}{ rs10508921 } & (TC vs TT) & 1.44 & $(0.43,4.88)$ & 0.99 & $(0.25,3.89)$ \\
\hline & (CC vs TT) & 3.54 & $(1.06,11.75)$ & 2.24 & $(0.55,9.13)$ \\
\hline rs651821 & (TC/CC vs TT) & 3.25 & $(1.35,7.84)$ & 1.29 & $(0.34,4.88)$ \\
\hline rs2075290 & (TC/CC vs TT) & 2.53 & $(1.01,6.31)$ & 0.77 & $(0.12,4.72)$ \\
\hline rs173539 & (CC vs TC/TT) & 2.97 & $(1.31,6.70)$ & 1.98 & $(0.67,5.90)$ \\
\hline rs1800591 & (GG vs TG/TT) & 2.97 & $(1.23,7.15)$ & 2.53 & $(0.88,7.27)$ \\
\hline rs35853021 & (TT vs TG/GG) & 2.63 & $(1.09,6.33)$ & 1.51 & $(0.52,4.36)$ \\
\hline rs9989419 & (GG vs $A G / A A)$ & 3.13 & $(1.39,7.08)$ & 1.68 & $(0.60,4.71)$ \\
\hline
\end{tabular}

$O R$, odds ratio; $\mathrm{Cl}$, confidence interval

*variants significant at $p<0.05$ using logistic regression analysis 
Table 3. SNPs with significant association with poor response to statin after variable selection

\begin{tabular}{lcccc} 
& Variable & Genotypic effect & Adjusted OR (95\% Cl) & $p$ value* \\
rs173539 & CC vs TC/TT & Recessive & $3.05(1.24,7.48)$ & 0.015 \\
rs1800591 & GG vs TG/TT & Recessive & $3.07(1.18,7.95)$ & 0.021 \\
rs1558861 & TC/CC vs TT & Dominant & $5.08(1.69,15.26)$ & 0.004 \\
\hline
\end{tabular}

OR, odds ratio; $\mathrm{Cl}$, confidence interval

*Significance set at $p<0.05$ after multiple logistic regression analysis and backward elimination variable selection

Table 4. The risk allele frequencies of SNPs associated with poor response to statin among Filipinos and other populations

\begin{tabular}{|c|c|c|c|c|c|c|c|c|}
\hline \multirow{2}{*}{ SNP } & \multirow{2}{*}{ Reference allele ${ }^{*}$} & \multirow{2}{*}{$\begin{array}{l}\text { Allele frequency for } \\
\text { study population }\end{array}$} & \multicolumn{6}{|c|}{ Allele frequencies for other ethnicities ${ }^{\dagger}$} \\
\hline & & & Global & AFR & AMR & EAS & EUR & SAS \\
\hline rs173539 & $\mathrm{C}$ & 0.56 & 0.67 & 0.59 & 0.68 & 0.77 & 0.70 & 0.64 \\
\hline rs1800591 & G & 0.71 & 0.75 & 0.74 & 0.82 & 0.86 & 0.74 & 0.61 \\
\hline rs1558861 & $\mathrm{C}$ & 0.46 & 0.13 & 0.01 & 0.13 & 0.24 & 0.09 & 0.19 \\
\hline
\end{tabular}

AF, allele frequency; AFR, Africans; AMR, admixed Americans; EAS, East Asians; EUR, Europeans; SAS, South Asians

${ }^{*}$ The reference allele used among the study population is the risk allele

†1000 Genomes Project Consortium. A global reference for human genetic variation. Nature. 2015 Oct;526(7571):68-74.

\section{RESULTS}

Thirty poor responders (cases) and 132 responders (controls) were included in the study. There was no difference in sex distribution between the two groups. One control was excluded due to low call rate (Figure 1A). Among the 136 candidate SNPs, 54 were removed based on significant Hardy-Weinberg disequilibrium and genotypic missingness test results. These variants underwent logistic regression analysis to determine the odds ratio.

There was no significant difference observed between statin poor responders and responders in terms of clinical factors (Table 1). The two groups were similar in terms of history of ischemic heart disease (OR 1.75; 95\% CI 0.79, $3.90 ; \mathrm{p}=0.17)$ and stroke (OR 2.09; 95\% CI 0.73, 5.98; $\mathrm{p}=$ 0.16). Most of the participants were on atorvastatin (48\%), followed by simvastatin (37\%), and rosuvastatin (15\%). More than half of the total participants were on moderateintensity statin therapy (65\%). Laboratory results showed a significant difference in the levels of LDL-c and total cholesterol. Higher levels of LDL-c $(p=0.0012)$ and total cholesterol $(\mathrm{p}=0.01)$ were observed among the cases, which reflect poor response to statins.

On allelic association analysis, there were $10 \mathrm{SNPs}$ with nominal allelic association with poor response to statin at $\alpha$ $=0.05$ on simple logistic regression (Table 2). However, none of the variants reached statistically significant association after adjusting for multiple testing (Bonferroni-adjusted $\alpha=$ 0.00061). Using Fisher's exact test, rs1800588 and rs662799 were not statistically significant.

On genotypic association analysis, 12 SNPs were found to have nominal genotypic association with poor response to statin at PCER $=0.05$ (Table 3). As in the previous step, none of the variants reached statistically significant association after adjustment for multiple testing (Bonferroni-adjusted $\alpha=0.00061)$ (Figure 1B). Chi-square analysis showed that rs1558861 and rs2075290 were nominally associated with poor response to statins; on Fisher's exact test; however, both SNPs lost statistical significance marginally (0.051 and 0.061 , respectively). Both SNPs were retained in the analysis since all cells satisfied assumptions for chisquare test of association. Also, the best possible genotypic effect changed from allelic to dominant for rs1800591 and rs651821 on Fisher's exact test; these were included in further analysis instead.

On univariate logistic regression analysis of clinical factors (Table 4), only hypertension (OR 2.10; CI 0.68, 6.48) demonstrated a $p$ value $\leq 0.2$. Meanwhile, $10 \mathrm{SNPs}$ have been nominally-associated with poor statin response $(\mathrm{p}<0.05)$ (Table 5). The crude and the adjusted ORs for these SNPs after multiple regression analysis as adjusted for hypertension are shown on Table 2 . Three variants were found with modest association for poor response to statins: rs173539 near CETP, rs1800591 in MTTP and rs1558861 located in the BUD13-ZPR1-APOA5 region (Table 3).

\section{DISCUSSION}

Genetic factors have been shown to affect responsiveness to statin therapy in different populations. The lack of reliable clinical predictors for poor response to statins highlights the possible utility of pharmacogenetic testing in dyslipidemia management. This study reports on the association of candidate genetic variants to poor response to statins on the background of traditional clinical correlates among Filipinos. The nominal association of three variants are highlighted; namely, rs173539 near CETP, rs1800591 in microsomal triglyceride transfer protein (MTTP) and rs1558861 located in the BUD13 homolog-ZPR1 zinc finger-apolipoprotein A5 (BUD13-ZPR1-APOA5) region. 
The variant rs 173539 is located $8 \mathrm{~kb}$ upstream of CETP in the intergenic region. This variant has been implicated in GWAS exploring lipid levels in ancestrally diverse cohorts. ${ }^{24}$ It has also been linked to the development of metabolic syndrome and cardiovascular disease risk factors in European ancestry individuals. ${ }^{25,26}$ Expression quantitative trait loci (eQTL) analysis published in the GenotypeTissue Expression (GTEx) Portal demonstrate a possible regulatory function of the variant on CETP expression in liver cells. CETP expression is shown to increase with every additional $\mathrm{C}$ allele. ${ }^{27}$ This protein is found in plasma, where it is involved in the transfer of cholesteryl ester from HDL-c to very low-density lipoprotein and LDL-c. The inhibition of CETP was shown to raise HDL-c levels and decrease LDL-c levels. ${ }^{28}$ A study by Suhy and colleagues in 2015 showed that the inhibition of CETP expression in both liver and spleen is significantly associated with the minor allele $\mathrm{T}$ of rs173539, while those with the $\mathrm{CC}$ genotype have higher CETP expression. ${ }^{29}$ It is possible that higher CETP expression may have caused LDL-c levels to rise, well beyond the statins' threshold for control. Further investigation is needed to verify the possible mechanisms involved.

Another highlighted polymorphism, rs1800591 $(-493 \mathrm{G}>\mathrm{T})$, is a promoter variant located in the first intron of MTTP. Expression studies using HepG2 cells revealed marked enhancement of transcriptional activity with the $T$ allele of the variant. ${ }^{30}$ The variant forms a haplotype with two other promoter polymorphisms, rs1800804 $(-164 \mathrm{~T}>\mathrm{C})$ and rs1800803 (-400A > T), which determine MTTP expression in intestinal and hepatic cells. MTTP is necessary for the formation and secretion of lipoproteins containing apolipoprotein B (apoB) from the intestine and liver. Apo B is responsible for the transfer and clearance of LDL-c and has effects on plasma levels. ${ }^{31}$

In this study, participants with the genotype GG of rs1800591 are found to have less LDL-c reductions compared to those with the genotype GT or TT in response to statins. The mechanism behind this association cannot be elucidated in the present study. However, it can be speculated from the roles of MTTP and ApoB that an impedance in the clearance of LDL-c can hinder the lowering effect of statins. It has been demonstrated that the $\mathrm{T}$ allele of the variant is associated with lower LDL-c serum levels in European ${ }^{32}$ and Chinese $^{33}$ populations. However, there has been conflicting data observed in a cohort of African American ${ }^{34}$ and Mexican subjects. ${ }^{35}$ Obesity and hyperinsulinemia likely modulate the effect of the variant on plasma lipoprotein levels and possibly account for the discrepancy. ${ }^{36}$ Regardless of the variant effect, $M T T P$-inhibitor drugs have been developed which have shown appreciable reductions in LDL-c levels in clinical trials. ${ }^{37}$

Lastly, rs1558861 is an intergenic variant located down-stream from the region containing BUD13, ZPR1 and $A P O A 5$ on chromosome 11. BUD13 codes for BUD13 homolog protein, which forms the RES (Retention and
Splicing) complex, together with SNIP and RBMX2. This complex is responsible for splicing regulation and nuclear retention of improperly spliced pre-mRNA. ${ }^{38}$ ZPR1 codes for a protein that is essential for normal nucleolar function in proliferating cells. ${ }^{39}$ APOA5 codes for an apolipoprotein component of high-density lipoprotein involved in regulating triglyceride levels in the plasma. Other variants in the $B U D 13-A P O A 5-Z P R 1$ region have been previously associated with attenuated response to statins of LDL-c and triglyceride levels among predominantly-white Americans of Northwestern ancestry, but the mechanisms remain unknown. ${ }^{40}$ The region is also implicated in studies on metabolic syndrome, dyslipidemia and diabetes mellitus, but currently, there are no other studies that directly associate rs1558861 with poor statin response. Meanwhile, an earlier extended genome-wide association study conducted to identify novel genetic determinants of LDL-c, HDL-c and TG levels and their associations in independent populations (including people of Indian Asian descent) has found that the $T$ allele of rs1558861 causes a 0.02-0.04-unit decrease in LDL-c. ${ }^{41}$ This is in line with the current study findings wherein allele $\mathrm{C}$ of the variant is associated with poorer LDL-c-reduction in response to statins under a dominant model. The allele $\mathrm{C}$ frequency among the study population is $46 \%$ which is markedly higher compared to other ethnicities (Table 4).

In addition, seven other variants were noted to be associated on univariate analysis which include rs776746 in (CYP3A5) and rs2032582 in ATP binding cassette subfamily $B$ member 1 ( $A B C B 1)$, which are associated with poor statin response among individuals of other ethnicities. ${ }^{42-45}$ The variant rs776746 is an allelic splice-acceptor $(6986 \mathrm{~T}>\mathrm{C})$ causing a decreased or absent CYP3A5 activity. The expression of this gene varies among different races, which may be indicative of its important role in influencing differences in drug clearance and response. ${ }^{46}$ On the other hand, rs2032582 $(2677 \mathrm{G}>\mathrm{T})$ is a missense variant in $A B C B 1, a$ gene involved in multidrug resistance ${ }^{47}$ which include statins and other drugs such as digoxin, chemotherapeutic agents, antiepileptics, and antiretrovirals. ${ }^{48}$

The rest of the variants have previously been found to correspond with lipid parameters across different ethnicities. This includes rs651821 in APOA5, rs2075290 in ZPR1 and rs9989419 near CETP. ${ }^{24}$ The variant rs35853021 in lipase $C$, hepatic type (LIPC) has been associated with HDL-c levels in a Finnish population. ${ }^{49}$ Lastly, the variant rs10508921 in $N$-acylsphingosine amidohydrolase 2 (ASAH2) has been implicated with thiazide-induced changes in triglyceride levels among African Americans. ${ }^{50}$ Although these variants did not retain statistical significance after multiple regression analysis with clinical factors, their notable association with lipid levels and statin response may warrant further investigation.

There are several limitations in this study. While all the drugs used belong to one drug class (statins), subtle 
differences in the pharmacokinetics of the varying types of statins may have been an additional confounding variable. Also, given the study design, the study focused on LDL-c reduction as the surrogate outcome measure for more clinically relevant outcomes such as mortality and adverse cardiovascular events, such as myocardial infarction and stroke. As the first study of its kind in the Filipino population, it serves as the springboard for future research that may be validated by prospective study designs, inclusion of clinical endpoints and adverse reactions, larger sample populations, and stratification according to specific subpopulations (e.g., diabetics, post-MI).

At present, guidelines still recommend statins as first-line therapy, with the addition of other drugs only if maximum dose is reached, in the background of suboptimal LDL-c reduction after 4-12 weeks of treatment. ${ }^{3}$ There are either no recommendations on the use of pharmacogenetic testing to guide statin treatment decision or some groups advise against its use due to lack of conclusive evidence., ${ }^{3,4}$ However, given that poor statin response may lead to further atheroma progression and clinical events, ${ }^{51}$ genetic testing has the potential to minimize delays resulting from trial of statin therapy with repeated monitoring of LDL-c levels. Physicians of patients who carry the identified alleles associated with poor response may be guided to immediately intensify or add effective, alternative therapy such as ezetimibe $^{51}$ or more recently, PCSK9 inhibitors. ${ }^{15,52}$

\section{CONCLUSION}

Genetic variants rs173539, rs1800591, and rs1558861 are associated with poor response to statins among Filipinos. Further study is recommended to test the external validity of the study in the general Filipino population.

\section{Acknowledgments}

This study was funded by the Philippine Council for Health Research and Development (PCHRD) of the Department of Science and Technology (DOST) through the Grants-In-Aid (GIA) Program. We thank all the laboratory and research staff and coordinators of the Institute of Human Genetics, National Institutes of Health, University of the Philippines, Manila and the Philippine Genome Center whose valuable contributions made this project possible.

\section{Statement of Authorship}

For conceptualization and methodology: RG Sy, EC Cutiongco-de la Paz, JB Nevado, FR Punzalan, EB Llanes, JA Magno, DD Ona, PM Reganit, LG Santos, and RP Tiongco.

For funding acquisition, project administration and supervision: RG Sy, EC Cutiongco-de la Paz, JB Nevado, and AL Aman.
For investigation: RG Sy, EC Cutiongco-de la Paz, JB Nevado, FR Punzalan, EB Llanes, JA Magno, DD Ona, PM Reganit, LG Santos, RP Tiongco, JM Aherrera, LL Abrahan, CF Agustin, AL Aman, and AP Bejarin.

For data curation and formal analysis: JB Nevado, AL Aman, and AP Bejarin.

For interpretation of data: RG Sy, EC Cutiongco-de la Paz, JB Nevado, FR Punzalan, EB Llanes, JA Magno, DD Ona, PM Reganit, LG Santos, RP Tiongco, JM Aherrera, LL Abrahan, CF Agustin, AL Aman, and AP Bejarin

Writing of original draft and visualization: JB Nevado, AL Aman, AP Bejarin, and LL Abrahan.

Revising the manuscript for significant intellectual content: RG Sy, EC Cutiongco-de la Paz, JB Nevado, and LG Santos.

All authors approved the final version of the manuscript to be published.

\section{Author Disclosure}

The following authors have no conflicts of interest to declare: Dr. Abrahan, Dr. Agustin, Dr. Aman, Dr. Bejarin, Dr. Cutiongco-de la Paz, Dr. Magno, Dr. Nevado, Dr. Punzalan, Dr. Reganit.

Dr. Aherrera: Received honoraria for lectures for Servier, Astrazeneca, GX International.

Dr. Llanes: Received honoraria for lectures for Servier, MSD, Bayer, Astrazeneca, Boehringer Ingelheim, Menarini, Novartis and LRI-Therapharma.

Dr. Ona: Received speaker grants from Astrazeneca, Servier, Viatris, Sanofi and Zydus; Advisory Board Member of Sanofi.

Dr. Santos: Past speaker for the following: Servier, Astrazeneca, MSD, LRI-Therapharma, OEP, Zuellig, Boehringer Ingelheim, Pascual Labs, Kanarb, Menarini, Ajanta, Torrent; Advisory Board Member of Zuellig and Kanarb.

Dr. Sy: Received research grants from MSD, Novartis, Pfizer and Servier; received honoraria for lectures for Astrazeneca, Corbridge, MSD, Novartis, Servier, LRITherapharma and Zuellig-Amgen; Advisory Board Member of Astrazeneca, MSD, Novartis, Pfizer, Servier and Zuellig-Amgen.

Dr. Tiongco: Past speaker for CME for ADP Pharma for levamlodipine molecule and 2019 CME module development for levamlodipine besylate with ADP Pharma. Past resource speaker on clopidogrel for Sanofi, and made a module for clopidogrel for Getz. Prepared module for best/ limited use for inclusion in clinical practice guidelines.

\section{Funding Source}

This paper and the project was funded by the Philippine Council on Health Research and Development of the Department of Science and Technology. 


\section{REFERENCES}

1. Food and Nutrition Research Institute-Department of Science and Technology (FNRI-DOST). Philippine Nutrition Facts and Figures 2013: Clinical and Health Survey. FNRI Bldg., DOST Compound, Bicutan, Taguig City, Metro Manila, Philippines. 2015.

2. World Health Organization. Global Health Estimates 2019. [Internet].2019[cited 2021 Jan]. Available from https://www.who.int/ data/global-health-estimates.

3. Stone NJ, Robinson JG, Lichtenstein AH, Bairey Merz CN, Blum CB, et al. 2013 ACC/AHA guideline on the treatment of blood cholesterol to reduce atherosclerotic cardiovascular risk in adults: a report of the American College of Cardiology/American Heart Association Task Force on Practice Guidelines. J Am Coll Cardiol. 2014 Jul 1; 63(25 Pt B):2889-934.

4. Perk J, De Backer G, Gohlke H, Graham I, Reiner Z, Verschuren M, et al. European Guidelines on cardiovascular disease prevention in clinical practice (version 2012). The Fifth Joint Task Force of the European Society of Cardiology and Other Societies on Cardiovascular Disease Prevention in Clinical Practice (constituted by representatives of nine societies and by invited experts). Eur Heart J. 2012 Jul; 33(13): 1635-701.

5. Liao JK. Safety and efficacy of statins in Asians. Am J Cardiol. 2007 Feb 1; 99(3):410-4.

6. Sasaki J, Arakawa K, Iwashita M, Matsushita Y, Kono S. Reduction in serum total cholesterol and risks of coronary events and cerebral infarction in Japanese men: the Kyushu Lipid Intervention Study. Circ J. 2003; 67:473-8.

7. Nakamura H. Management of elevated cholesterol in the primary prevention group of adult Japanese (MEGA study). Circulation. 2005; 112(21):3364.

8. Ito H, Ouchi Y, Ohashi Y, Saito Y, Ishikawa T, Nakamura H, et al. A comparison of low versus standard dose pravastatin therapy for the prevention of cardiovascular events in the elderly: the Pravastatin AntiAtherosclerosis Trial in the Elderly (PATE). J Atheroscler Thromb. $2001 \mathrm{Feb} ; 8(2): 33-44$.

9. Ishikawa T, Ito H, Ouchi Y, Ohashi Y, Saito Y, Nakamura H, et al. Increased risk for cardiovascular outcomes and effect of cholesterollowering pravastatin therapy in patients with diabetes mellitus in the Pravastatin Anti-Atherosclerosis Trial in the Elderly (PATE). Curr Ther Res. 2005; 66(1):48-65.

10. Saito Y, Shirai K, Sasaki N, Shinomiya M, Yoshida S. Prognosis of hypercholesterolemic patients taking pravastatin for five years: the Chiba Lipid Intervention Program (CLIP) Study. J Atheroscler Thromb. 2002 Nov; 9(2):99-108.

11. Koizumi J, Shimizu M, Miyamoto S, Origasa H, Mabuchi H. Effect of pravastatin-induced LDL-cholesterol reduction on coronary heart disease and cerebrovascular disease in Japanese: Hokuriku Lipid Coronary Heart Disease Study-Pravastatin Atherosclerosis Trial (Holicos-PAT). J Atheroscler Thromb. 2002 Jun; 9(5):251-259.

12. Matsuzaki M, Kita T, Mabuchi H, Matsuzawa Y, Nakaya N, Oikawa $\mathrm{S}$, et al. Large scale cohort study of the relationship between serum cholesterol concentration and coronary events with low-dose simvastatin therapy in Japanese patients with hypercholesterolemia. Circ J. 2002 Dec; 66(12):1087-95.

13. Igl W, Johansson Å, Wilson JF, Wild SH, Polašek O, Hayward C, et al. Modeling of environmental effects in genome-wide association studies identifies SLC2A2 and HP as novel loci influencing serum cholesterol levels. PLoS Genet. 2010 Jan; 6(1):e1000798.

14. Pasanen MK, Fredrikson H, Neuvonen PJ, Niemi M. Different effects of SLCO1B1 polymorphism on the pharmacokinetics of atorvastatin and rosuvastatin. Clin Pharmacol Ther. 2007 Dec; 82(6):726-33.

15. Chaudhary R, Garg J, Shah N, Sumner A. PCSK9 inhibitors: A new era of lipid lowering therapy. World J Cardiol. 2017 Feb; 9(2):76-91.

16. Boekholdt SM, Sacks FM, Jukema JW, Shepherd J, Freeman DJ, $\mathrm{McMahon} \mathrm{AD}$, et al. Cholesteryl ester transfer protein TaqIB variant, high-density lipoprotein cholesterol levels, cardiovascular risk, and efficacy of pravastatin treatment: individual patient meta-analysis of 13,677 subjects. Circulation. 2005 Jan; 111(3): 278-87.
17. van Venrooij FV, Stolk RP, Banga JD, Sijmonsma TP, van Tol A, Erkelens DW, et al. Common cholesteryl ester transfer protein gene polymorphisms and the effect of atorvastatin therapy in type 2 diabetes. Diabetes Care. 2003 Apr; 26(4):1216-23.

18. Fiegenbaum M, da Silveira FR, Van der Sand CR, Van der Sand LC, Ferreira ME, Pires RC, et al. Pharmacogenetic study of apolipoprotein $\mathrm{E}$, cholesteryl ester transfer protein and hepatic lipase genes and simvastatin therapy in Brazilian subjects. Clin Chim Acta. 2005 Dec; 362(1-2):182-8.

19. Sy RG, Cutiongco EM, Punzalan FE, Santos RS, Geronimo FR, Tangco RV. Human cholestryl ester transfer protein (TaqIB) polymorphism among Filipinos with cardiovascular risk factors. J Atheroscler Thromb. 2007 Jun; 14(3):116-21.

20. Feng Q, Wei WQ, Chung CP, Levinson RT, Bastarache L, Denny JC, et al. The effect of genetic variation in PCSK9 on the LDLcholesterol response to statin therapy. Pharmacogenomics J. 2017 Mar; 17(2): 204-8.

21. Dong B, Wu M, Li H, Kraemer FB, Adeli K, Seidah NG, et al. Strong induction of PCSK9 gene expression through HNF1 $\alpha$ and SREBP2: mechanism for the resistance to LDL-cholesterol lowering effect of statins in dyslipidemic hamsters. J Lipid Res. 2010 Jun; 51(6): 1486-95.

22. Sy RG, Nevado JB, Llanes EJB, Magno JDA, Ona DID, Cutiongco - de la Paz EMC, et al. The Klotho Variant rs36217263 Is associated with poor response to cardioselective beta-blocker therapy among Filipinos. Clin Pharmacol Ther. 2020 Jan; 107(1):221-6.

23. Reganit PFM, Nevado JB, Cutiongco-de la Paz EMC, Taquiso JL, Aman AYCL, Sy RG, et al. BAG6 Variant rs805303 is nominally associated with ACEi-induced cough among Filipinos. Phil J Sci. 2020 Mar; 149(1):35-41.

24. Hoffmann TJ, Theusch E, Haldar T, Ranatunga DK, Jorgenson E, Medina MW, et al. A large electronic-health-record-based genomewide study of serum lipids. Nat Genet. 2018 Mar;50(3):401.

25. Kraja AT, Vaidya D, Pankow JS, Goodarzi MO, Assimes TL, Kullo IJ, et al. A bivariate genome-wide approach to metabolic syndrome: STAMPEED consortium. Diabetes. 2011 Apr 1; 60(4):1329-39.

26. Middelberg RP, Ferreira MA, Henders AK, Heath AC, Madden PA, Montgomery GW, et al. Genetic variants in LPL, OASL and TOMM40/APOE-C1-C2-C4 genes are associated with multiple cardiovascular-related traits. BMC Med Genet. 2011 Dec; 12(1):123.

27. Lonsdale J, Thomas J, Salvatore M, Phillips R, Lo E, Shad S, et al. The genotype-tissue expression (GTEx) project. Nat Genet. 2013 May 29; 45(6):580-5.

28. Kosmas CE, Frishman WH. New and Emerging LDL CholesterolLowering Drugs. Am J Ther. 2015 May 1; 22(3):234-41.

29. Suhy A, Hartmann K, Papp A, Wang D, Sadee W. Regulation of CETP expression by upstream polymorphisms: Reduced expression associated with rs247616. Pharmacogenet Genomics. 2015 August; 25(8):394-401.

30. Karpe F, Lundahl B, Ehrenborg E, Eriksson P, Hamsten A. A common functional polymorphism in the promoter region of the microsomal triglyceride transfer protein gene influences plasma LDL levels. Arterioscler Thromb Vasc Biol. 1998 May; 18(5):756-61.

31. Leung GK, Véniant MM, Kim SK, Zlot CH, Raabe M, Björkegren J, et al. A deficiency of microsomal triglyceride transfer protein reduces apolipoprotein B secretion. J Biol Chem. 2000 Mar 17; 275(11): 7515-20.

32. Ledmyr H, Karpe F, Lundahl B, McKinnon M, Skoglund-Andersson C, Ehrenborg E. Variants of the microsomal triglyceride transfer protein gene are associated with plasma cholesterol levels and body mass index. J Lipid Res. 2002 Jan; 43(1):51-8.

33. Pan SL, Luo XQ, Lu ZP, Lu SH, Luo H, Liu CW, et al. Microsomal triglyceride transfer protein gene-493G/T polymorphism and its association with serum lipid levels in Bama Zhuang long-living families in China. Lipids Health Dis. 2012 Dec; 11(1):177.

34. Juo SH,Han Z, Smith JD, Colangelo L, Liu K. Common polymorphism in promoter of microsomal triglyceride transfer protein gene influences cholesterol, ApoB, and triglyceride levels in young African American men: results from the coronary artery risk development in young 
adults (CARDIA) study. Arterioscler Thromb Vasc Biol. 2000 May; 20(5):1316-22.

35. Gonzalez-Becerra K, Ramos-Lopez O, Garcia-Cazarin ML, BarronCabrera E, Panduro A, Martinez-Lopez E. Associations of the lipid genetic variants Thr54 (FABP2) and-493T (MTTP) with total cholesterol and low-density lipoprotein cholesterol levels in Mexican subjects. J Int Med Res. 2018 Apr; 46(4):1467-76.

36. St-Pierre J, Lemieux I, Miller-Felix I, Prud'homme D, Bergeron J, Gaudet D, et al. Visceral obesity and hyperinsulinemia modulate the impact of the microsomal triglyceride transfer protein $-493 \mathrm{G} / \mathrm{T}$ polymorphism on plasma lipoprotein levels in men. Atherosclerosis. $2002 \mathrm{Feb} ; 160(2): 317-24$.

37. Sahebkar A, Watts GF. New LDL-cholesterol lowering therapies: pharmacology, clinical trials, and relevance to acute coronary syndromes. Clin Ther. 2013 Aug; 35(8):1082-98.

38. Wysoczanski P, Zweckstetter M. Retention and splicing complex (RES)-the importance of cooperativity. RNA Biol. 2016; 13(2): 128-33.

39. Galcheva-Gargova Z, Gangwani L, Konstantinov KN, Mikrut M, Theroux SJ, Enoch T, et al. The cytoplasmic zinc finger protein ZPR1 accumulates in the nucleolus of proliferating cells. Mol Biol Cell. 1998 Oct; 9(10):2963-71.

40. O'Brien SE, Schrodi SJ, Ye Z, Brilliant MH, Virani SS, Brautbar A. Differential lipid response to statins is associated with variants in the BUD13-APOA5 Gene region. J Cardiovasc Pharmacol. 2015 Aug; 66(2):183-8.

41. Waterworth DM, Ricketts SL, Song K, Chen L, Zhao JH, Ripatti $\mathrm{S}$, et al. Genetic variants influencing circulating lipid levels and risk of coronary artery disease. Arterioscler Thromb Vasc Biol. 2010 Nov; 30(11):2264-76.

42. Kivistö KT, Niemi M, Schaeffeler E, Pitkälä K, Tilvis R, Fromm MF, et al. Lipid-lowering response to statins is affected by CYP3A5 polymorphism. Pharmacogenetics. 2004 Aug; 14(8):523-5.

43. Kolovou G, Kolovou V, Ragia G, Mihas C, Diakoumakou O, Vasiliadis I, et al. CYP3A5 genotyping for assessing the efficacy of treatment with simvastatin and atorvastatin. Genet Mol Biol. 2015 May; 38(2):129-37.
44. Mega JL, Morrow DA, Brown A, Cannon CP, Sabatine MS. Identification of genetic variants associated with response to statin therapy. Arterioscler Thromb Vasc Biol. 2009 Sep; 29(9):1310-5.

45. Bercovich D, Friedlander Y, Korem S, Houminer A, Hoffman A, Kleinberg L, et al. The association of common SNPs and haplotypes in the CETP and MDR1 genes with lipids response to fluvastatin in familial hypercholesterolemia. Atherosclerosis. 2006 Mar; 185(1): 97-107.

46. Kuehl P, Zhang J, Lin Y, Lamba J, Assem M, Schuetz J, et al. Sequence diversity in CYP3A promoters and characterization of the genetic basis of polymorphic CYP3A5 expression. Nat Genet. 2001 Apr; 27(4): 383-91.

47. Rebecchi IM, Rodrigues AC, Arazi SS, Genvigir FD, Willrich MA, Hirata $\mathrm{MH}$, et al. $\mathrm{ABCB} 1$ and $\mathrm{ABCC} 1$ expression in peripheral mononuclear cells is influenced by gene polymorphisms and atorvastatin treatment. Biochem Pharmacol. 2009 Jan; 77(1):66-75.

48. Leschziner GD, Andrew T, Pirmohamed M, Johnson MR. ABCB1 genotype and PGP expression, function and therapeutic drug response: a critical review and recommendations for future research. Pharmacogenomics J. 2007 Jun; 7(3):154-79.

49. Kettunen J, Tukiainen T, Sarin AP, Ortega-Alonso A, Tikkanen E, Lyytikäinen LP, et al. Genome-wide association study identifies multiple loci influencing human serum metabolite levels. Nat Genet. 2012 Mar; 44(3):269-76.

50. Del-Aguila JL, Beitelshees AL, Cooper-Dehoff RM, Chapman $\mathrm{AB}$, Gums JG, Bailey K, et al. Genome-wide association analyses suggest NELL1 influences adverse metabolic response to HCTZ in African Americans. Pharmacogenomics J. 2014 Feb; 14(1):35-40.

51. Kataoka Y, St. John J, Wolski K, Uno K, Puri R, Tuzcu EM, et al. Atheroma progression in hyporesponders to statin therapy. Arterioscler Thromb Vasc Biol. 2015 Apr; 35(4):990-5.

52. Sabatine MS, Giugliano RP, Keech AC, Honarpour N, Wiviott $\mathrm{SD}$, Murphy SA, et al. Evolocumab and clinical outcomes in patients with cardiovascular disease. N Engl J Med. 2017 May 4; 376(18): 1713-22. 